\title{
QUALIDADE FÍSICA E BACTERIOLÓGICA DE OVOS OPACOS DE CODORNAS SANITIZADOS, REFRIGERADOS E CONTAMINADOS EXPERIMENTALMENTE POR Salmonella enterica SER. TYPHIMURIUM
}

\author{
PHYSICAL AND MICROBIOLOGICAL QUALITY OF OPAQUE, \\ SANITIZED, AND CHILLED QUAIL EGGS EXPERIMENTALLY \\ CONTAMINATED WITH Salmonella enteric SER. TYPHIMURIUM
}

\author{
Maria Juliana Ribeiro Lacerda ${ }^{1}$ \\ Nadja Susana Mogyca Leandro ${ }^{*}$ \\ Maria Auxiliadora Andrade ${ }^{1}$ \\ Juliana Bonifácio Alcântara ${ }^{1}$ \\ Maria Luiza Ferreira Stringhini² \\ Marcos Barcellos Café ${ }^{1}$

\begin{abstract}
${ }^{1}$ Escola de Veterinária e Zootecnia da Universidade Federal de Goiás, Goiânia, GO, Brasil. 2Faculdade de Nutrição da Universidade Federal de Goiás, Goiânia, GO, Brasil.

*Autora para correspondência - mogyca@ufg.br
\end{abstract}

\section{Resumo}

Objetivou-se estudar a qualidade física, química e microbiológica de ovos de codornas contaminados artificialmente com Salmonella enterica ser. Typhimurium, sanitizados e armazenados a diferentes temperaturas $\left(5\right.$ e $25^{\circ} \mathrm{C}$ ), durante 27 dias. Foram utilizados 768 ovos com cascas opacas e peso médio de $11 \mathrm{~g}$. O delineamento foi inteiramente casualizado em esquema fatorial 2x2x2 (contaminação $\mathrm{x}$ sanitização x refrigeração) com seis repetições e um ovo por parcela. Os ovos foram contaminados pelo manuseio com $1,5 \times 10^{5}$ unidade formadoras de colônias (UFCs) e, de acordo com os tratamentos, foram sanitizados com solução com $5 \mathrm{ppm}$ de $\mathrm{Cl}$. Os dados foram submetidos à análise de variância e teste t. A contaminação bacteriana prejudicou o peso do ovo, $\mathrm{uH}$, índice de gema e de albume e $\mathrm{pH}$ de gema e de albume, a partir de 18 dias de armazenamento. O tempo de estocagem dos ovos e a temperatura de armazenamento influenciaram a qualidade interna dos ovos de codornas em todas as variáveis estudadas. A pior qualidade interna foi observada em ovos armazenados na temperatura de $25^{\circ} \mathrm{C}$. A sanitização e a refrigeração reduziram o crescimento da Salmonella nos ovos contaminados. Ovos com casca opaca, quando não refrigerados, devem ser consumidos em até 18 dias após a postura. Palavras-chave: casca opaca; estocagem; ovos de codornas; Salmonella enterica ser. Typhimurium; sanitização.

\begin{abstract}
The objective of this study was to verify the physical, chemical and microbiological quality of Japanese quail eggs artificially contaminated with Salmonella enterica ser. Typhimurium. The eggs were sanitized and stored at different temperatures (between 5 and $25^{\circ} \mathrm{C}$ ) for 27 days. We used 768 eggs with opaque shells, typical pigments of the species, and average weight of $11 \mathrm{~g}$. The experimental design was completely randomized in a $2 \times 2 \times 2$ factorial arrangement (contamination $\mathrm{x}$ sanitation $\mathrm{x}$ cooling) with six replications and one egg per experimental unit. The eggs were contaminated by handling with $1.5 \times 10^{5}$ colony forming unit (CFU) of Salmonella. Typhimurium / $\mathrm{mL}$ and sanitized according to the treatments with a $5 \mathrm{ppm} \mathrm{Cl}$ solution. The data were subjected to analysis of variance and $t$ test. Bacterial contamination has damaged the egg weight, Haugh unit, yolk index and albumen,
\end{abstract}


and $\mathrm{pH}$ of yolk and albumen, from 18 days of storage. The egg storage time and storage temperature affected the internal quality of quail eggs in all variables. The worst internal quality was observed in eggs stored at $25^{\circ} \mathrm{C}$. The sanitation and cooling reduced the growth of Salmonella in contaminated eggs. Eggs in opaque shell, when not refrigerated, should be consumed within 18 days after laying. Keywords: opaque shell; quail eggs; Salmonella Typhimurium; sanitization; storage.

Enviado em: 16 maio 2012

Aceito em: 25 novembro 2015

\section{Introdução}

O consumo de ovos de codornas tem aumentado nos últimos anos e estima-se que o consumo do brasileiro esteja aproximadamente em 9,5 ovos per capta por ano. A produção de ovos de qualidade é um fator de relevância, uma vez que é a qualidade que determina o sucesso do produto no mercado consumidor. Moura et al. ${ }^{(1)}$ relataram que a alimentação e a saúde humana caminham juntos e observaram mudanças no consumidor, que tem exigido produtos de qualidade diferenciada, higienizados, bem embalados e sem injúrias.

A procura dos consumidores por ovos de qualidade leva todos os envolvidos no processo de produção e distribuição de ovos a se preocuparem não só com as características externas, como peso, cor, integridade da casca e uniformidade, mas também com a manutenção da qualidade interna do ovo, que decresce logo após a postura ${ }^{(2)}$. Bordin et al. ${ }^{(3)}$ relataram que, embora a coturnicultura tenha se destacado no setor produtivo pelo amplo crescimento da atividade no Brasil, a legislação atual não faz menção à qualidade dos ovos de codornas, sendo a classificação específica para ovos de galinhas. Por outro lado, os produtos de origem animal podem ser veículos de importantes patógenos responsáveis por infecções alimentares como a salmonelose ${ }^{(4)}$, já que relatos mostraram alta incidência dessa bactéria em codornas e na contaminação de ovos no mercado ${ }^{(5)}$.

O processo de lavagem resulta em ovos de melhor aparência para comercialização e influencia na aceitação do produto pelo consumidor. De acordo com Stringhini et al. ${ }^{(6)}$, outra vantagem da lavagem é a sanitização da casca, diminuindo a probabilidade de micro-organismos penetrarem pelos poros, contaminando o conteúdo dos ovos e, ainda, eliminando o risco de patógenos ao ser humano. No entanto, esses autores consideram a remoção da cutícula dos poros da casca como uma desvantagem do procedimento de lavagem dos ovos, o que facilita a entrada de micro-organismos, resultando na deterioração e diminuição do período de estocagem.

De acordo com Souza et al. ${ }^{(7)}$ e Scott e Silversidest ${ }^{(8)}$, quanto maior o tempo e a temperatura de armazenamento, pior a qualidade interna dos ovos. A refrigeração dos ovos durante a estocagem visa a retardar a velocidade de multiplicação de micro-organismos e aumentar a vida de prateleira do produto, sendo obrigatória em muitos países ${ }^{(9)}$. Entretanto, nas condições do mercado interno brasileiro, $92 \%$ dos ovos são comercializados in natura sem refrigeração.

Stringhini et al. ${ }^{(6)}$ verificaram que a refrigeração não evitou a penetração de Pseudomonas aeruginosa no ovo de galinha, pois os ovos contaminados experimentalmente na casca e refrigerados durante o armazenamento apresentaram essa bactéria no conteúdo. No entanto, o processo de refrigeração controlou a multiplicação de Pseudomonas aeruginosa na casca por até 30 dias, mas não foi eficiente para evitar a multiplicação bacteriana no conteúdo.

Os ovos de codornas no Brasil são produzidos, em sua maioria, por pequenos produtores, os quais não utilizam nenhum método de sanitização, assim como não refrigeram os ovos durante a estocagem antes da comercialização. Existem poucas informações científicas sobre qualidade de ovos de codornas e o Ministério da Agricultura e da Agência Rural não apresentam nenhuma normatização específica.

Portanto, a presente pesquisa foi desenvolvida com o intuito de avaliar a qualidade físico-química e microbiológica de ovos de codornas com casca opaca, submetidos à sanitização, contaminados artificialmente com Salmonella enterica ser. Typhimurium e armazenados sob-refrigeração ou temperatura ambiente durante 27 dias. 


\section{Material e Métodos}

Foram utilizados 384 ovos de codornas da linhagem Japonesa, coletados diretamente do galpão de produção de uma granja comercial (no final do período vespertino), com o cuidado de padronizar o tamanho e o tipo de casca (opaca com pigmentos típicos da espécie), sendo que essa seleção foi realizada de maneira subjetiva através da visualização da casca do ovo. Após a coleta e seleção, os ovos foram transportados para o laboratório onde foram mantidos em temperatura ambiente e submetidos à radiação ultravioleta por 24 horas, com o objetivo de eliminar as possíveis bactérias, da casca, provenientes da granja. Foram utilizados 48 ovos para a avaliação da qualidade interna no tempo zero.

Os tratamentos foram uma combinação de três fatores (inoculação dos ovos com a bactéria, sanitização da casca e temperatura de armazenamento). O delineamento utilizado foi inteiramente casualizados em esquema fatorial $2 \times 2 \times 2$, totalizando oito tratamentos com seis repetições, sendo o ovo considerado como a unidade experimental.

Os ovos do grupo contaminado foram inoculados na casca com Salmonella enterica ser. Typhimurium. O inóculo foi preparado com Salmonella enterica ser. Typhimurium isolada no Laboratório de Bacteriologia, em 2009, a partir de amostras oriundas de codornas, sendo que a concentração do inóculo foi de $1,0 \times 10^{6} \mathrm{UFC} / \mathrm{mL}$. Para obtenção do inóculo, a cepa foi repicada em ágar verde brilhante e incubada a $37^{\circ} \mathrm{C}$ por $18-24 \mathrm{~h}$. Em seguida, as células foram suspensas em solução salina tamponada a $0,85 \%$, mantidas a $4{ }^{\circ} \mathrm{C}$ e concentração de $1,0 \times 10^{6} \mathrm{UFC} / \mathrm{mL}$ ajustada com auxílio da escala de Mac Farland ${ }^{(10)}$ e a concentração foi confirmada pelo plaqueamento das diluições decimais seriadas em ágar verde brilhante, com posterior incubação a $37^{\circ} \mathrm{C}$ e contagem das UFC de Salmonella enterica ser. Typhimurium.

Os ovos foram inoculados por exposição ao inóculo por contato com as mãos revestidas com luvas descartáveis, simulando possível contaminação cruzada dos ovos. Com auxílio de uma seringa de tuberculina com $0,1 \mathrm{~mL}$ de solução salina tamponada a $0,85 \%$ contendo a concentração de Salmonella enterica ser. Typhimurium desejada, foi depositado $0,05 \mathrm{~mL}$ diretamente nos ovos, em seguida foi espalhado com as mãos revestidas com luvas. Cada ovo foi mantido por um período de aproximadamente 10 segundos nas mãos sendo umedecidos, tendo sua superfície totalmente molhada pela solução.

Após a inoculação, os ovos passaram por fluxo laminar por 15 minutos para secagem da casca. Os ovos do grupo experimental sanitizados foram desinfetados com solução de cloro a 5 ppm, utilizandose um "borrifador de água".

$\mathrm{O}$ armazenamento dos ovos do grupo refrigerado foi realizado à temperatura de $5{ }^{\circ} \mathrm{C}$ em geladeira e umidade relativa de $60 \%$ e o dos ovos do grupo não refrigerados foi realizado à temperatura de $25^{\circ} \mathrm{C}$ em estufa B.O.D. O período de armazenamento total do experimento foi de 27 dias, sendo que a cada nove dias 96 ovos foram avaliados quanto à qualidade física e microbiológica.

As variáveis de qualidade física dos ovos foram peso do ovo, gravidade específica, espessura de casca, porcentagem da gema, albúmen e casca, unidade Haugh, porcentagem de perda de peso, índice de gema, índice do albúmen, $\mathrm{pH}$ do albúmen e gema.

Para a análise microbiológica dos ovos, foram analisados pools de três cascas e três conteúdos por unidade experimental. Os procedimentos de análise microbiológica utilizados seguiram a Instrução Normativa no 62, de 26 de Agosto de 2003 do Ministério da Agricultura Pecuária e Abastecimento ${ }^{(11)}$. Após realizar o plaqueamento por superfície com $0,1 \mathrm{~mL}$ da diluição de cascas e conteúdo (gema e albúmen) em ágar MacConkey e Hectoen. As placas foram incubadas a $37^{\circ} \mathrm{C}$ por $18-24$ horas e, logo após, foi realizada a contagem de bactérias da casca (Citrobacteriaceae, Enterobacteriaceae e Pseudomonas). Já para o conteúdo, foi verificada apenas presença ou ausência da Salmonella enterica ser. Typhimurium.

Os resultados foram submetidos à análise de variância e foi aplicada regressão polinomial considerando-se o período de armazenamento dos ovos. Todas as análises foram realizadas fazendose uso do programa computacional Statistical Analisys System ${ }^{(12)}$. 


\section{Resultados e Discussão}

No tempo inicial, ou seja, antes da inoculação, sanitização e do armazenamento, foi realizada análise da qualidade física, química e microbiológica dos ovos opacos e os resultados indicaram que os ovos eram homogêneos. A gravidade específica variou de 1,070 a 1,075 para todos os ovos analisados, indicando boa qualidade de casca; o peso do ovo foi de $11,10 \mathrm{~g}$; índice de albume foi 0,12 e de gema, 0,45; $\mathrm{pH}$ de albume, 7,66 e gema, 5,71; e $\mathrm{uH}=93,97$. Os resultados mostraram que os valores médios de qualidade externa e interna foram compatíveis com ovos frescos de codornas japonesas ${ }^{(13)}$.

No período de nove dias de armazenamento (Tabela 1), pôde-ser observar que não houve interação $(p>0,05)$ entre os fatores contaminação, sanitização e temperatura para índice de albume, porcentagem de albume e gema, $\mathrm{pH}$ de gema e unidade Haugh. Entretanto, constatou-se que houve efeito $(\mathrm{p}<0,05)$ da temperatura de estocagem sobre índice de gema e porcentagem de gema, sendo que os ovos não refrigerados apresentaram diminuição da qualidade física em relação aos refrigerados.

Tabela 1: Valores médios de peso do ovo (PO), índice de albume (IA), porcentagem de albume $(\mathrm{A} \%), \mathrm{pH}$ de albume ( $\mathrm{pH} \mathrm{A}$ ), índice de gema (IG), porcentagem de gema (G\%), $\mathrm{pH}$ de gema ( $\mathrm{pH}$ $\mathrm{G})$, unidade Haugh (uH) de ovos de codornas inoculados, sanitizados e armazenados sob diferentes temperaturas por nove dias

\begin{tabular}{lcccccccc}
\hline Grupos experimentais & \multicolumn{7}{c}{ Variáveis Estudadas } \\
\hline Inoculação & $\mathrm{PO}(\mathrm{g})$ & $\mathrm{IA}$ & $\mathrm{A}(\%)$ & $\mathrm{pH}(\mathrm{A})$ & $\mathrm{IG}$ & $\mathrm{G}(\%)$ & $\mathrm{pH}(\mathrm{G})$ & $\mathrm{UH}$ \\
\hline Não inoculado & 11,08 & 0,06 & 44,24 & 10,10 & 0,37 & 33,89 & 7,73 & $83,77 \mathrm{~b}$ \\
Inoculado & 10,80 & 0,07 & 46,62 & 9,59 & 0,37 & 34,33 & 7,83 & $85,68 \mathrm{a}$ \\
\hline Sanitização & & & & & & & & \\
\hline Não Sanitizado & 10,83 & 0,07 & 45,28 & 9,63 & 0,36 & $35,21 \mathrm{a}$ & 7,94 & 84,86 \\
Sanitizado & 11,05 & 0,07 & 45,57 & 10,06 & 0,37 & $33,01 \mathrm{~b}$ & 7,62 & 84,59 \\
\hline Temperatura & & & & & & & & \\
\hline $25^{\circ} \mathrm{C}$ & 10,47 & $0,06 \mathrm{~b}$ & 46,55 & 9,96 & 0,33 & $35,34 \mathrm{a}$ & 7,81 & 84,09 \\
$5^{\circ} \mathrm{C}$ & 11,47 & $0,07 \mathrm{a}$ & 44,31 & 9,73 & 0,40 & $32,88 \mathrm{~b}$ & 7,75 & 85,36 \\
\hline Valores de p & & & & & & & & \\
\hline Inoc. & $0,037^{*}$ & 0,187 & 0,139 & 0,066 & 0,730 & 0,601 & 0,571 & $0,046^{*}$ \\
San. & 0,106 & 0,929 & 0,856 & 0,118 & 0,158 & $0,010^{*}$ & 0,105 & 0,776 \\
Refrig. & $0,0001^{*}$ & $0,031^{*}$ & 0,163 & 0,384 & $0,0001^{*}$ & $0,004^{*}$ & 0,730 & 0,179 \\
San.*Refrig. & $0,0001^{*}$ & 0,789 & 0,491 & 0,775 & 0,960 & 0,237 & 0,144 & 0,800 \\
Inoc.*San. & $0,031^{*}$ & 0,067 & 0,135 & 0,252 & 0,404 & 0,892 & 0,500 & 0,274 \\
Inoc.*Refrig. & $0,0001^{*}$ & 0,187 & 0,716 & $0,047^{*}$ & $0,048^{*}$ & 0,460 & 0,115 & 0,334 \\
Inoc.*San.*Refrig. & 0,353 & 0,331 & 0,277 & 0,690 & 0,461 & $0,042^{*}$ & 0,310 & 0,074 \\
\hline CV (\%) & 4,13 & 22,32 & 12,02 & 9,50 & 7,79 & 8,37 & 8,44 & 3,80 \\
\hline
\end{tabular}

Médias seguidas de letras iguais na mesma coluna não diferem pelo teste $\mathrm{F}(5 \%)$ em cada grupo experimental.

* = significância

Para peso dos ovos (Figura 1-A), houve interação $(p<0,05)$ entre inoculação e temperatura após nove dias de armazenamento. Ovos refrigerados apresentaram valores de peso de ovos maiores $(p<0,05)$ que os não-refrigerados. Os ovos contaminados com Salmonella enterica ser. Typhimurium e mantidos sob refrigeração não apresentaram diferença em relação aos não contaminados; no entanto, quando não foram refrigerados, o peso dos ovos do grupo contaminado foi menor do que o do grupo não contamindo $(\mathrm{p}<0,05)$ (Figura 1-A).

Houve interação entre os grupos inoculados e sanitizados $(\mathrm{p}<0,05)$; ovos inoculados apresentaram menor peso $(p<0,05)$ quando sanitizados (Figura 1-B). Esses dados sugerem que a sanitização favoreceu 
a perda de peso de ovos quando contaminados. A perda de peso dos ovos está correlacionada com o número e dimensão dos poros, a espessura ou resistência da casca e com as condições ambientais; no entanto, uma alta concentração de poros, ou poros com diâmetros grandes, causa um efeito negativo devido à maior possibilidade de sua desidratação ${ }^{(14)}$. A redução de peso dos ovos pode ser determinada pela provável perda de amônia, nitrogênio e sulfeto de hidrogênio que são produtos da degradação química de seus constituintes orgânicos ${ }^{(15)}$.

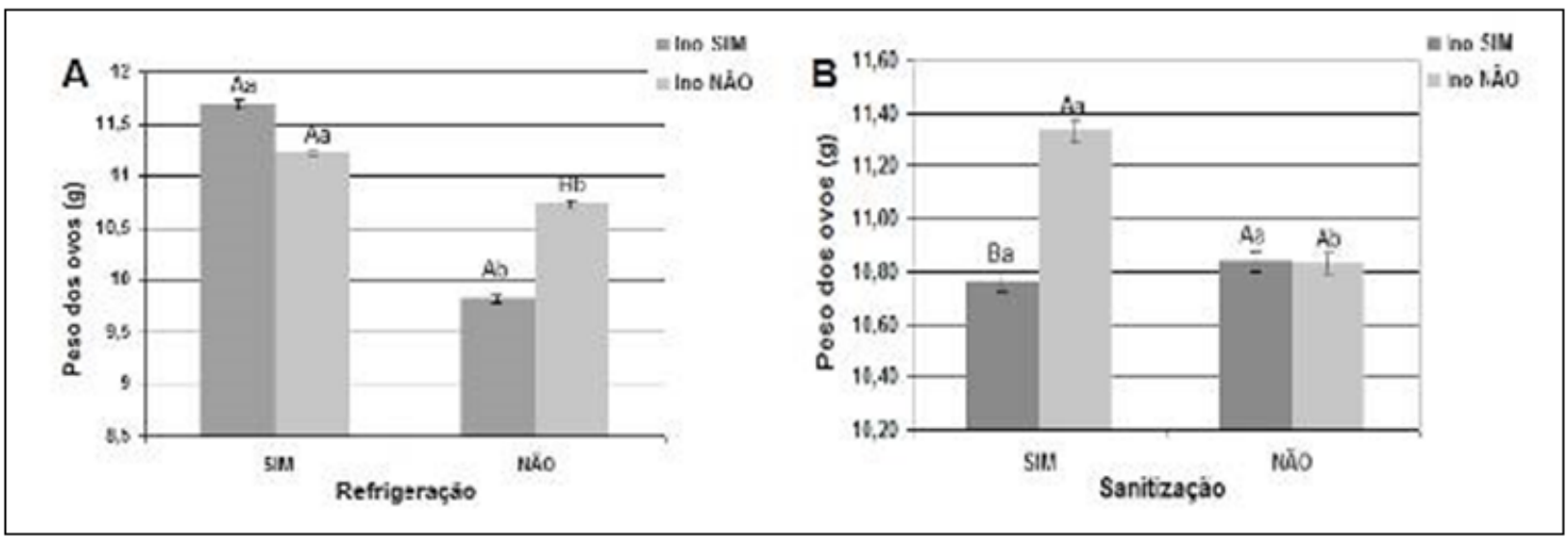

Figura 1: Interação de peso do ovo entre inoculação com Salmonella enterica ser. Typhimurium e refrigeração (A), inoculação e sanitização (B) e armazenamento por nove dias. Letras maiúsculas equivalem a médias estatisticamente diferentes no grupo refrigeração e letras minúsculas ao grupo inoculado (Fig.A). Letras maiúsculas equivalem ao grupo sanitizado e letras minúsculas ao grupo inoculado (Fig.B).

A redução do peso do ovo durante o armazenamento, segundo Samli et al. ${ }^{(16)}$, ocorre devido à transferência de umidade do albume para o ambiente externo por meio dos poros da casca, sendo que a velocidade da evaporação da água depende diretamente da temperatura e da ventilação do ambiente. Pinto e Silva ${ }^{(17)}$ constataram perda de peso de 1,04 g em ovos de poedeiras comerciais, lavados e contaminados com Salmonella Enteritides e mantidos a $8{ }^{\circ} \mathrm{C}$ por 14 dias. De acordo com esses autores, essa perda foi em decorrência da retirada da cutícula de proteção pela escovação durante a lavagem dos ovos, o que influenciou a velocidade de evaporação de água. Neste experimento, os ovos sanitizados, quando refrigerados, perderam mais peso do que os ovos não sanitizados; no entanto, os ovos de codornas sanitizados foram submetidos apenas à aspersão da água com 5 ppm de cloro.

Para a variável pH de albume (Figura 2), houve interação $(\mathrm{p}<0,05)$ entre inoculação e refrigeração após nove dias de armazenamento. Quando os ovos foram refrigerados não houve efeito da contaminação sobre o $\mathrm{pH}$; no entanto, em ovos não refrigerados, os dados sugerem que a presença da bactéria piorou a qualidade do albúmen (aumento do $\mathrm{pH}$ ). As mudanças de $\mathrm{pH}$, segundo Figueiredo et al. ${ }^{(18)}$, ocorrem nos primeiros dias após a postura e o declínio da sua qualidade é acelerado por altas temperaturas de armazenamento. Pinto e Silva ${ }^{(17)}$ citaram que o comportamento do $\mathrm{pH}$ do albume sofre alterações durante o período de armazenamento em altas temperaturas. Quando o ovo torna-se velho, ocorre a liberação de dióxido de carbono, aumentando os valores de $\mathrm{pH}$ em ovos de poedeiras, sendo que o albume sofre um clareamento e perde a viscosidade ${ }^{(16)}$. 


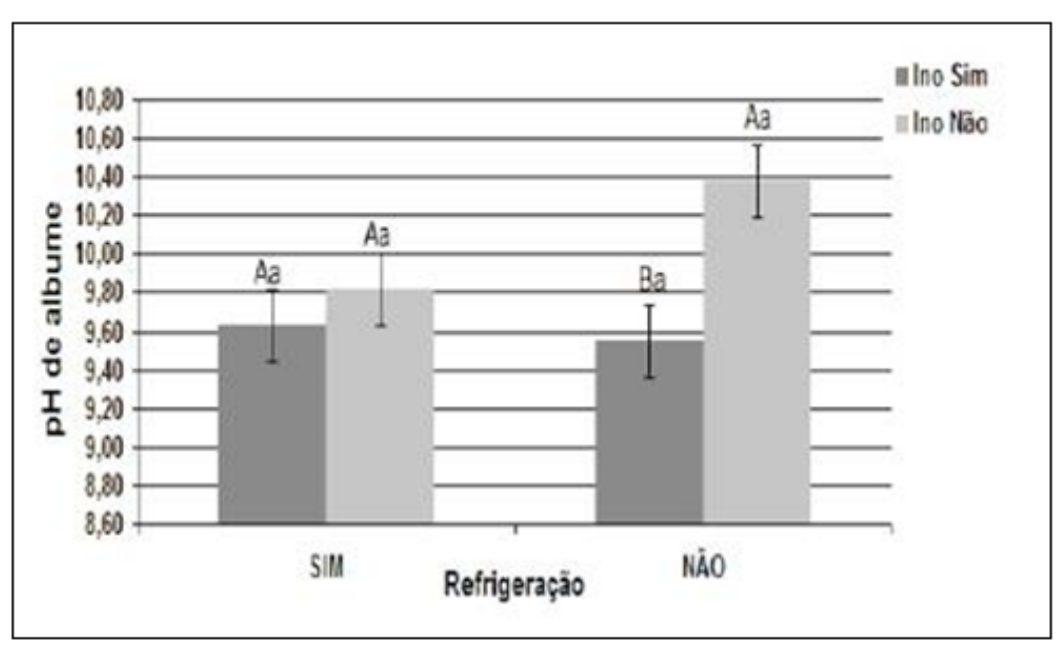

Figura 2: Desdobramento da interação significativa de $\mathrm{pH}$ de albume entre inoculação de ovos com Salmonella enterica ser. Typhimurium e refrigeração por nove dias de armazenamento. Letras minúsculas equivalem ao grupo refrigeração e letras maiúsculas ao grupo inoculação.

Para o período de armazenamento de 18 dias (Tabela 2) pôde-se observar que não houve interação $(\mathrm{p}>0,05)$ entre os grupos estudados para as variáveis índice de albume e gema, porcentagem de albume e gema, $\mathrm{pH}$ de albume e gema e unidade Haugh. Entretanto, foi constatado que houve efeito $(\mathrm{p}<0,05)$ da temperatura de estocagem sobre o índice de albume e gema, porcentagem de albume e gema, $\mathrm{pH}$ de albume e gema e unidade Haugh, sendo que os ovos não refrigerados apresentaram diminuição da qualidade física em relação aos refrigerados.

Tabela 2: Valores médios de peso do ovo (PO), índice de albume (IA), porcentagem de albume (A\%), $\mathrm{pH}$ de albume ( $\mathrm{pH}$ A), índice de gema (IG), porcentagem de gema ( $\mathrm{G} \%), \mathrm{pH}$ de gema (pH $\mathrm{G})$, unidade Haugh $(\mathrm{uH})$ de ovos de codornas inoculados, sanitizados e armazenados sob diferentes temperaturas por 18 dias

\begin{tabular}{lcccccccc}
\hline Grupos experimentais & \multicolumn{7}{c}{ Variáveis Estudadas } \\
\hline Inoculação & $\mathrm{PO}(\mathrm{g})$ & $\mathrm{IA}$ & $\mathrm{A}(\%)$ & $\mathrm{pH}(\mathrm{A})$ & $\mathrm{IG}$ & $\mathrm{G}(\%)$ & $\mathrm{pH}(\mathrm{G})$ & $\mathrm{UH}$ \\
\hline Não inoculado & 10,85 & 0,06 & 30,59 & 10,35 & 0,34 & 34,70 & $7,28 \mathrm{a}$ & 83,01 \\
Inoculado & 10,87 & 0,06 & 29,77 & 10,34 & 0,34 & 35,43 & $7,64 \mathrm{~b}$ & 82,46 \\
\hline Sanitização & & & & & & & & \\
\hline Não Sanitizado & 10,88 & 0,06 & 29,82 & 10,35 & 0,34 & $36,05 \mathrm{a}$ & 7,40 & 82,57 \\
Sanitizado & 10,84 & 0,06 & 30,53 & 10,35 & 0,34 & $34,08 \mathrm{~b}$ & 7,52 & 82,91 \\
\hline Temperatura & & & & & & & & \\
\hline $25^{\circ} \mathrm{C}$ & 10,27 & $0,04 \mathrm{~b}$ & $27,62 \mathrm{~b}$ & $10,48 \mathrm{a}$ & $0,26 \mathrm{~b}$ & $36,64 \mathrm{a}$ & $7,66 \mathrm{a}$ & $80,40 \mathrm{~b}$ \\
$5^{\circ} \mathrm{C}$ & 11,45 & $0,08 \mathrm{a}$ & $32,74 \mathrm{a}$ & $10,21 \mathrm{~b}$ & $0,42 \mathrm{a}$ & $33,49 \mathrm{~b}$ & $7,26 \mathrm{~b}$ & $85,07 \mathrm{a}$ \\
\hline Valores de p & & & & & & & & \\
\hline Inoc. & 0,812 & 0,414 & 0,582 & 0,359 & 0,644 & 0,526 & $0,007^{*}$ & 0,581 \\
San. & 0,648 & 0,743 & 0,655 & 0,959 & 0,539 & $0,043^{*}$ & 0,340 & 0,735 \\
Refrig. & $0,0001^{*}$ & $0,0001^{*}$ & $0,001^{*}$ & $0,0001^{*}$ & $0,0001^{*}$ & $0,001^{*}$ & $0,003^{*}$ & $0,0001^{*}$ \\
San. ${ }^{*}$ Refrig. & $0,0001^{*}$ & 0,414 & 0,153 & 0,540 & 0,817 & 0,832 & 0,377 & 0,289 \\
Inoc.*San. & $0,0001^{*}$ & 0,414 & 0,084 & 0,682 & 0,700 & 0,641 & 0,728 & 0,214 \\
Inoc.*Refrig. & $0,0001^{*}$ & 0,743 & 0,854 & 0,064 & 0,590 & 0,167 & 0,095 & 0,761 \\
Inoc.*San.*Refrig. & 0,784 & 0,743 & 0,618 & 0,959 & 1,000 & 0,375 & 0,146 & 0,625 \\
\hline CV (\%) & 2,16 & 26,94 & 3,45 & 0,54 & 10,84 & 2,07 & 5,97 & 4,16 \\
\hline
\end{tabular}

Médias seguidas de letras iguais na mesma coluna não diferem pelo teste $\mathrm{F}(5 \%)$ em cada grupo experimental.

* = significância 
Houve interação $(p<0,05)$ para o peso dos ovos (Figura 3-A) entre os fatores inoculação e refrigeração, sendo que as contaminações bacterianas em ovos não refrigerados proporcionaram menor peso dos ovos. A evaporação da água do ovo é um processo contínuo, tendo início no momento da postura e não cessando até que esteja completamente desidratado. A velocidade da perda de peso é acelerada em altas temperaturas ${ }^{(19)}$ e retardada por alta umidade relativa $(75 \text { a } 80 \%)^{(20)}$.

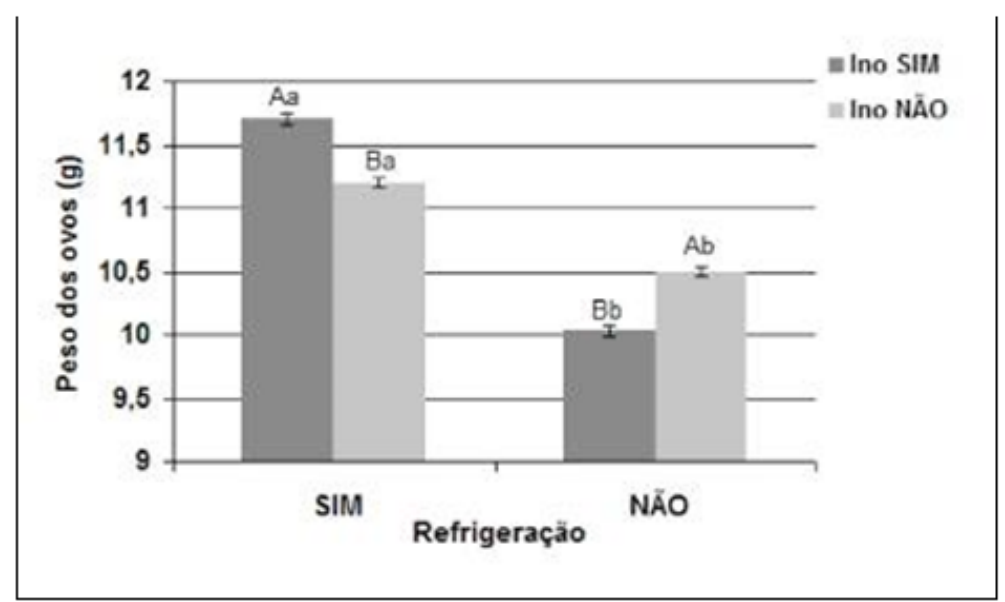

Figura 3: Interação significativa para peso de ovo entre inoculação e refrigeração quando armazenados por 18 dias. Letras minúsculas equivalem ao grupo refrigeração e letras maiúsculas ao grupo sanitização (Fig. A). Letras minúsculas equivalem ao grupo refrigeração e letras maiúsculas ao grupo inoculação (Fig.B).

No período de 27 dias de armazenamento (Tabela 3) não houve interação ( $p>0,05)$ entre os fatores estudados para as variáveis: índice de albume e gema, porcentagem de albume, gema e unidade Haugh. Entretanto, constatou-se que houve efeito da temperatura de estocagem $(p<0,05)$ sobre o índice de albume e de gema, porcentagem de albume e de gema e unidade Haugh, sendo que os ovos não refrigerados apresentaram diminuição da qualidade física em relação aos refrigerados. Jones e Musqrove ${ }^{(21)}$ verificaram perda de qualidade em ovos refrigerados por períodos longos (10 semanas). Houve efeito da inoculação $(\mathrm{p}<0,05)$ para as variáveis porcentagem de albume e $\mathrm{pH}$ de gema.

Houve interação $(\mathrm{p}<0,05)$ para o $\mathrm{pH}$ de albume (Figura 4-A) entre sanitização e refrigeração. Quando os ovos foram refrigerados, melhores resultados puderam ser observados no grupo sanitizado (Figura 4-A), ou seja, quando não há possibilidade da refrigeração, a sanitização é uma alternativa que ajuda a manter a qualidade de albume. No entanto, Mendes et al. ${ }^{(20)}$, estudando ovos de poedeiras, verificaram que a refrigeração foi mais importante que a sanitização, já que não encontraram efeito da sanitização, independentemente da refrigeração.

Sabrani e Payne ${ }^{(22)}$, quando armazenaram ovos com casca íntegra a $12^{\circ} \mathrm{C}$ e a $28{ }^{\circ} \mathrm{C}$, observaram que o $\mathrm{pH}$ do albume piorou mais rapidamente em ovos armazenados em altas temperaturas. O albume tem seu potencial hidrogeniônico alterado rapidamente após a postura, aumentando o $\mathrm{pH}$ de 7,5 em ovos frescos para 9,5 após a primeira semana de armazenamento. Leandro et al. ${ }^{(23)}$ também encontraram um aumento no $\mathrm{pH}$ dos ovos de poedeiras armazenados em temperatura ambiente.

Para a mesma variável (Figura 5-B), houve interação $(p<0,05)$ entre a inoculação a e sanitização. Ovos não inoculados apresentaram piores resultados do que os inoculados, independentemente da sanitização; esse fato pode estar relacionado com a presença de outras bactérias como: Citrobacteriaceae, Enterobacteriaceae e Pseudomonas. 
Tabela 3: Valores médios de peso do ovo de casca opaca (PO), índice de albume (IA), porcentagem de albume (A\%), $\mathrm{pH}$ de albume ( $\mathrm{pH}$ A), índice de gema (IG), porcentagem de gema ( $\mathrm{G} \%), \mathrm{pH}$ de gema $(\mathrm{pH} \mathrm{G})$, unidade Haugh $(\mathrm{uH})$, contaminados ou não, sanitizados ou não e armazenados sob diferentes temperaturas por 27 dias

\begin{tabular}{lcccccccc}
\hline Grupos experimentais & \multicolumn{7}{c}{ Variáveis Estudadas } \\
\hline Inoculação & $\mathrm{PO}(\mathrm{g})$ & $\mathrm{IA}$ & $\mathrm{A}(\%)$ & $\mathrm{pH}(\mathrm{A})$ & $\mathrm{IG}$ & $\mathrm{G}(\%)$ & $\mathrm{pH}(\mathrm{G})$ & $\mathrm{UH}$ \\
\hline Não inoculado & 10,67 & 0,05 & $36,76 \mathrm{~b}$ & 9,04 & 0,30 & 39,19 & $6,58 \mathrm{a}$ & 80,03 \\
Inoculado & 10,59 & 0,06 & $41,36 \mathrm{a}$ & 8,44 & 0,30 & 38,47 & $5,97 \mathrm{~b}$ & 81,93 \\
\hline Sanitização & & & & & & & & \\
\hline Não Sanitizado & 10,59 & 0,06 & 40,10 & 8,70 & 0,30 & 40,02 & 6,40 & 81,48 \\
Sanitizado & 10,67 & 0,06 & 38,02 & 8,78 & 0,30 & 37,64 & 6,16 & 80,48 \\
\hline Temperatura & & & & & & & & \\
\hline $25^{\circ} \mathrm{C}$ & 10,01 & $0,04 \mathrm{~b}$ & $35,70 \mathrm{~b}$ & 8,73 & $0,23 \mathrm{~b}$ & $40,44 \mathrm{a}$ & 6,42 & $77,12 \mathrm{~b}$ \\
$5^{\circ} \mathrm{C}$ & 11,25 & $0,08 \mathrm{a}$ & $42,42 \mathrm{a}$ & 8,75 & $0,37 \mathrm{a}$ & $37,22 \mathrm{~b}$ & 6,13 & $84,83 \mathrm{a}$ \\
\hline Valores de p & & & & & & & & \\
\hline Inoc. & 0,249 & 0,272 & $0,003^{*}$ & $0,0001^{*}$ & 0,571 & 0,594 & $0,0001^{*}$ & 0,096 \\
San. & 0,271 & 1,000 & 0,159 & 0,054 & 0,677 & 0,069 & $0,021^{*}$ & 0,372 \\
Refrig. & $0,0001^{*}$ & $0,0001^{*}$ & $0,0001^{*}$ & 0,760 & $0,0001^{*}$ & $0,019 *$ & $0,005^{*}$ & $0,0001^{*}$ \\
San.*Refrig. & $0,0001^{*}$ & 0,528 & 0,610 & $0,0001^{*}$ & 0,969 & 0,115 & $0,0001^{*}$ & 0,152 \\
Inoc.*San. & $0,0001^{*}$ & 0,345 & 0,978 & $0,0003^{*}$ & 0,909 & 0,145 & 0,211 & 0,255 \\
Inoc.*Refrig. & $0,0001^{*}$ & 0,087 & 0,469 & 0,505 & 0,850 & 0,275 & 0,550 & 0,117 \\
Inoc.*San.*Refrig. & 0,331 & 0,345 & 0,077 & $0,0001^{*}$ & 0,244 & 0,552 & $0,0001^{*}$ & 0,136 \\
\hline CV (\%) & 2,47 & 29,62 & 3,18 & 1,71 & 12,42 & 2,73 & 5,49 & 4,76 \\
\hline
\end{tabular}

Médias seguidas de letras iguais na mesma coluna não diferem pelo teste $\mathrm{F}(5 \%)$ em cada grupo experimental.

* = significância

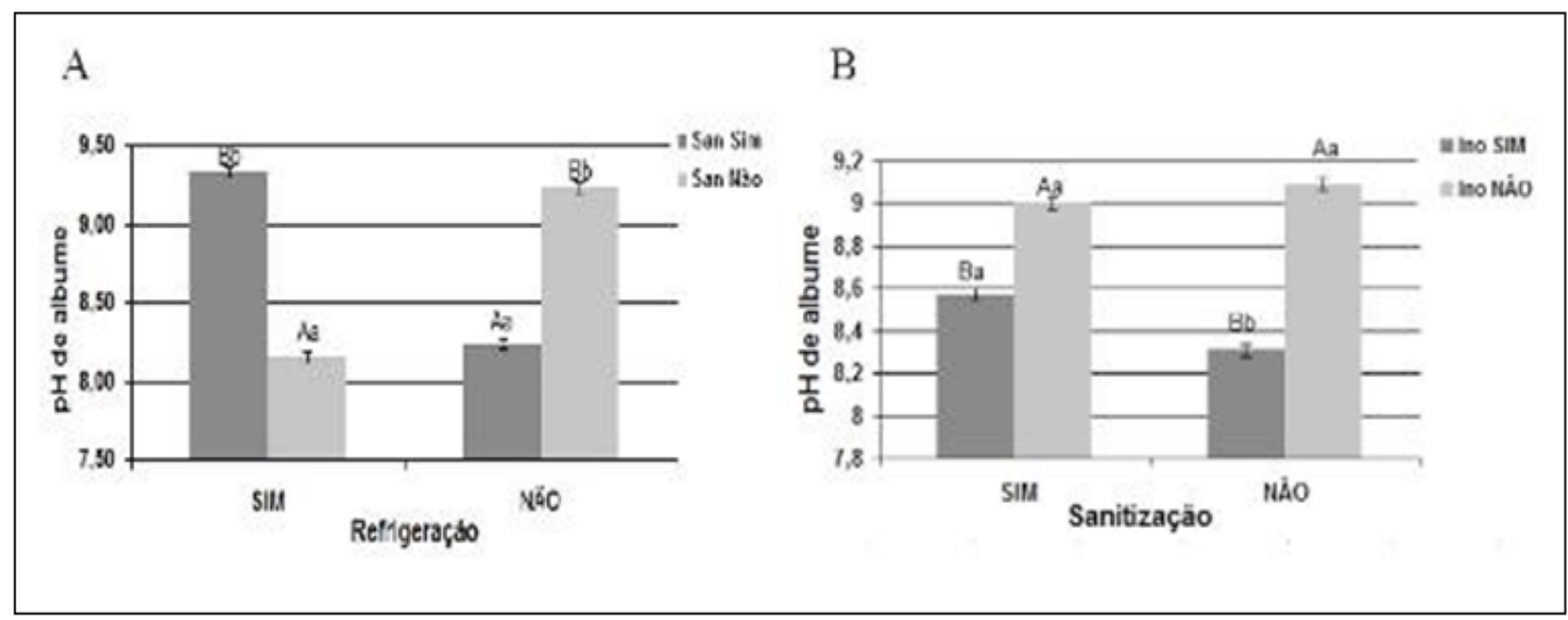

Figura 4; Desdobramento das interações significativas de $\mathrm{pH}$ de albume entre sanitização e refrigeração (A) e entre inoculação e sanitização (B) armazenados por 27 dias. Letras minúsculas equivalem ao grupo refrigeração e letras maiúsculas ao grupo sanitização (Fig.A). Letras minúsculas equivalem ao grupo sanitizado e letras maiúsculas ao grupo inoculado (Fig.B). 
Na Figura 5-A está demonstrado um estudo de regressão em relação ao tempo de armazenamento (período total estudado - 27 dias) para unidade Haugh, dos ovos submetidos a refrigeração, inoculação e sanitização, e na Figura 5-B, de ovos não submetidos à sanitização. Os tratamentos sanitizados, combinados com inoculação ou com a refrigeração, apresentaram regressão linear negativa (Figura 5-A). Pôde-se observar que, aos 18 e 27 dias após o armazenamento, houve diferença entre as retas dos ovos refrigerados em relação aos ovos não refrigerados, mostrando um maior declínio para ovos não refrigerados. Do mesmo modo, os tratamentos não sanitizados, combinados com os outros fatores, apresentaram regressão linear negativa (Figura 5-B), sendo que ovos refrigerados apresentaram melhor valor do que ovos não refrigerados. Entretanto, não houve efeito da inoculação, mostrando que a presença da Salmonella enterica ser. Typhimurium não prejudicou a qualidade de UH. Do mesmo modo, Mendes et al. ${ }^{(20)}$ observaram que ovos de poedeiras contaminados com Pseudomonas aeruginosa e armazenados sob-refrigeração apresentaram melhores resultados de unidade Haugh, independentemente da contaminação; relataram ainda que a refrigeração foi capaz de manter a qualidade dos ovos mesmo contaminados.

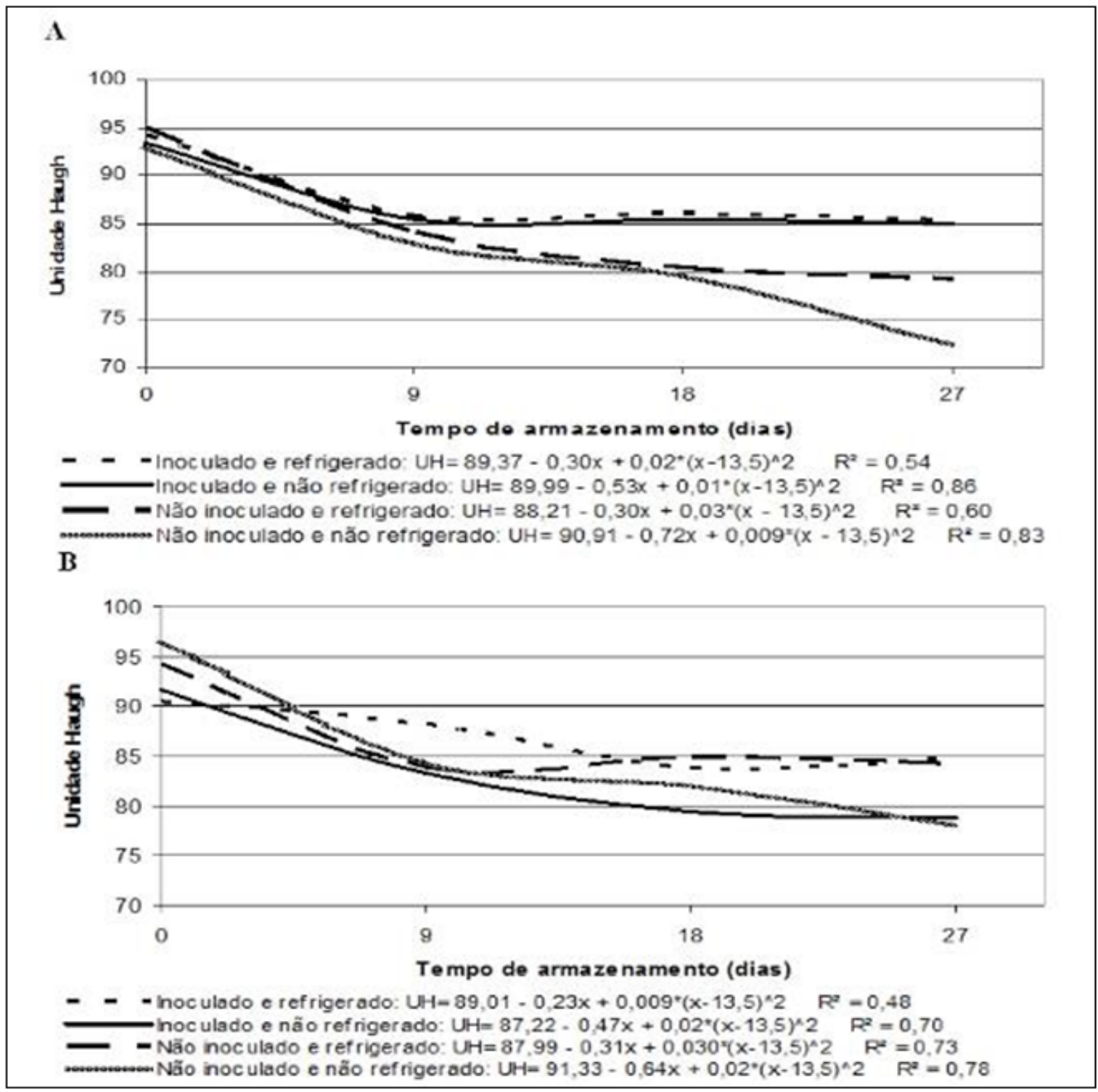

Figura 5: $\mathrm{A}=$ representa o grupo dos sanitizados e $\mathrm{B}=$ grupo não sanitizado. Valores da unidade Haugh dos ovos submetidos aos tratamentos de inoculação e refrigeração a $5{ }^{\circ} \mathrm{C}$; inoculado e não refrigerado $=25{ }^{\circ} \mathrm{C}$; não inoculado e refrigerado a $5{ }^{\circ} \mathrm{C}$; não inoculado e não refrigerado $=25{ }^{\circ} \mathrm{C}$ durante 27 dias de armazenamento. 
Os dados com relação ao estudo da contagem das UFC/g de bactérias (Citrobacteriaceae, Enterobacteriaceae e Pseudomonas) nas cascas dos ovos submetidos aos diferentes tratamentos, de acordo com o tempo de armazenamento (nove, 18 e 27 dias), estão apresentados na Tabela 4. Pôde-se observar valores de UFCs de colônias de bactérias entre 61,8 (2,55 log) a 32.457,9 (4,51 $\log$ ), mostrando que mesmo os tratamentos nos quais os ovos não foram contaminados apresentaram bactérias como as Citrobacteriaceae, Enterobacteriaceae e Pseudomonas com nove dias após o armazenamento, sendo que no tempo zero a metodologia de eliminar bactérias na casca com ultra violeta foi eficiente.

Não houve efeito $(p>0,05)$ dos fatores estudados sob a quantidade de colônias das bactérias para os ovos armazenados por até nove dias. No entanto, Stringhini et al. ${ }^{(6)}$, estudando o comportamento da bactéria Pseudomonas aeruginosas em ovos de poedeiras, verificaram que os ovos do tratamento contaminado com maior concentração de bactéria $\left(7,8 \times 10^{2} \mathrm{UFCs} / \mathrm{mL}\right)$ e armazenados a $25{ }^{\circ} \mathrm{C}$ apresentaram maior contagem da bactéria tanto na casca como no conteúdo aos 10 dias de armazenamento. As diferenças nos resultados podem estar relacionadas com as diferentes espécies de bactéria estudadas, concentração do inóculo, tipo do ovo (poedeira x codorna), entre outros.

Tabela 4: Valores médios da contagem de UFC das bactérias Citrobacteriaceae, Enterobacteriaceae e Pseudomonas encontradas nas cascas de ovos opacos, inoculados, sanitizados e armazenados sob diferentes temperaturas por 27 dias

\begin{tabular}{lccc}
\hline \multicolumn{1}{c}{ Grupos Experimentais } & \multicolumn{3}{c}{$\begin{array}{c}\text { Dias de armazenamento } \\
\text { N }\end{array}$} \\
\hline Inoculação & $\mathbf{0 9}$ & $\mathbf{1 8}$ & $\mathbf{2 7}$ \\
\hline Não inoculado & $6.361,30$ & 358,10 & 580,40 \\
Inoculado & $10.863,70$ & $34.801,60$ & $28.613,40$ \\
\hline Sanitização & & & 6.166 \\
\hline Não Sanitizado & $6.121,30$ & $31.359,10$ \\
Sanitizado & $11.103,60$ & $3.800,30$ & $28.613,40$ \\
\hline Temperatura & & & 29.132 \\
\hline $25^{\circ} \mathrm{C}$ & $11.145,60$ & $32.457,90$ & 61,80 \\
$5^{\circ} \mathrm{C}$ & $6.079,40$ & $2.701,80$ & $0,042^{*}$ \\
\hline Valor de p ${ }^{1}$ & & & 0,209 \\
\hline Inoc. & 0,703 & $0,004^{*}$ & $0,035^{*}$ \\
San. & 0,673 & 0,355 & 0,208 \\
Refrig. & 0,668 & 0,220 & 0,234 \\
San. ${ }^{*}$ Refrig. & 0,157 & 0,776 & $0,042^{*}$ \\
Ino. ${ }^{*}$ San. & 0,171 & $0,042^{*}$ & 0,234 \\
Ino. ${ }^{*}$ Refrig. & 0,167 & $0,017^{*}$ & 253,39 \\
Ino. ${ }^{*}$ San. ${ }^{*}$ Refrig. & 0,709 & 0,495 &
\end{tabular}

${ }^{1}$ Dados foram transformados em log para a análise estatística pelo teste $F(p<0,05)$.

* = significância

Houve interação $(\mathrm{p}<0,05)$ para a inoculação e sanitização aos 18 dias de armazenamento e para a inoculação e refrigeração aos 18 e 27 dias de armazenamento para presença de bactérias na casca de ovos opacos (Tabela 5). Os ovos submetidos à inoculação e sanitização tiveram números menores $(\mathrm{p}<0,05)$ de bactérias quando comparados com os ovos inoculados e não sanitizados (Tabela 5), mostrando que a sanitização pode ser um inibidor de crescimento Salmonella enterica ser. Typhimurium. 
Houve interação $(p<0,05)$ entre os fatores de inoculação e refrigeração no tempo de 18 dias de armazenamento. Os ovos inoculados e refrigerados tiveram menor quantidade de bactérias quando comparado aos ovos inoculados e não refrigerados. Do mesmo modo, a refrigeração mostrou um efeito positivo sobre a inibição do desenvolvimento de colônias de bactérias (Citrobacteriaceae, Enterobacteriaceae e Pseudomonas) na casca de ovos opacos (Tabela 5). Stringhini et al. ${ }^{(6)}$, estudando o comportamento da bactéria Pseudomonas aeruginosa, na casca de ovos de poedeiras, após 20 dias de estocagem, observaram que a refrigeração no armazenamento não foi capaz de controlar o crescimento bacteriano na casca dos grupos contaminados experimentalmente.

Ovos armazenados por 27 dias apresentaram interação para a inoculação e refrigeração e pôdese observar que os ovos refrigerados, independentemente da contaminação, apresentaram menor crescimento de colônias de bactérias do que os não-refrigerados. Ovos contaminados e não refrigerados apresentaram o pior resultado, já que o resultado reflete a presença da Salmonella enterica ser. Typhimurium mais bactérias do ambiente (Tabela 5).

Os valores aceitáveis de bactérias nas cascas de ovos não foram estabelecidos pelo Ministério da Agricultura, Pecuária e Abastecimento. É desejável a menor carga bacteriana na casca a fim de diminuir o risco de penetração do micro-organismo no conteúdo. A contagem em placas de bactérias mesófilas é comumente empregada para indicar a qualidade sanitária dos alimentos ${ }^{(6)}$.

Tabela 5: Desdobramento das interações significativas entre contaminação de ovos com Citrobacteriaceae, Enterobacteriaceae e Pseudomonas em cascas de ovos opacos, sanitizados e armazenamento sob diferentes temperaturas por 18 e 27 dias

\begin{tabular}{|c|c|c|}
\hline \multicolumn{3}{|c|}{18 dias de armazenamento } \\
\hline & \multicolumn{2}{|c|}{ contaminação } \\
\hline & $\operatorname{sim}$ & não \\
\hline Sim sanitização & $6.899,25 \mathrm{Ab}$ & $7.101,87 \mathrm{Ab}$ \\
\hline \multirow[t]{3}{*}{ Não sanitização } & $72.703,88 \mathrm{Ba}$ & $14,37 \mathrm{Ab}$ \\
\hline & \multicolumn{2}{|c|}{ contaminação } \\
\hline & $\operatorname{sim}$ & não \\
\hline Sim refrigeração & $120,75 \mathrm{Bb}$ & $48,80 \mathrm{Ab}$ \\
\hline \multirow[t]{4}{*}{ Não refrigeração } & $64.795,10 \mathrm{Aa}$ & $595,50 \mathrm{Ab}$ \\
\hline & \multicolumn{2}{|c|}{27 dias de armazenamento } \\
\hline & \multicolumn{2}{|c|}{ contaminação } \\
\hline & $\operatorname{sim}$ & não \\
\hline Sim refrigeração & $33 \mathrm{Bb}$ & $90,62 \mathrm{Ab}$ \\
\hline Não refrigeração & $57.193,70 \mathrm{Aa}$ & $1.070,20 \mathrm{Ab}$ \\
\hline
\end{tabular}

Na Tabela 6 estão mostrados os valores de Unidade Formadora de Colônias (UFCs) de Salmonella enterica ser. Typhimurium na casca de ovos opacos, contaminados, sanitizados e estocados à temperatura de $5{ }^{\circ} \mathrm{C}$ ou $25^{\circ} \mathrm{C}$, no tempo 9, 18 e 27 dias após o armazenamento. Avaliações bacteriológicas das cascas e do conteúdo de ovos realizados no tempo zero, anteriormente à aplicação do inóculo, não detectaram a presença de Salmonella enterica ser. Typhimurium, mostrando que o manejo na inoculação dos ovos foi correto. Além disso, os ovos do grupo experimental controle (sem contaminação de Salmonella enterica ser. Typhimurium) permaneceram negativos bacteriologicamente durante os 27 dias de armazenamento.

Aos 9 e 18 dias houve efeito $(p<0,05)$ da inoculação, mostrando que nos ovos que não inoculados não houve presença de Salmonella enterica ser. Typhimurium. Ainda aos 18 dias de armazenamento, houve interação $(p<0,05)$ entre a sanitização e a refrigeração, mostrando que ovos mantidos sob refrigeração, quando não sanitizados, obtiveram maiores valores de UFCs quando comparados aos 
ovos sanitizados (Tabela 6). Assim, considerando-se o desenvolvimento da Salmonella pôde-se inferir que tanto a sanitização como a refrigeração foram importantes no controle da Salmonella e, portanto, na qualidade bacteriológica do ovo.

Mendes et al. ${ }^{(20)}$ e Stringhini et al. ${ }^{(6)}$ verificaram que, em ovos lavados, a carga bacteriana foi menor em relação aos ovos não lavados. Jones et al. ${ }^{(24)}$ observaram que ovos lavados apresentaram melhor qualidade microbiológica de casca e de conteúdo que os não lavados nas análises de mesófilos, bolores e leveduras, Enterobacteriaceae e Pseudomonas spp. quando armazenados por 10 semanas a $4{ }^{\circ} \mathrm{C}$.

Tabela 6: Valores médios de contagem de colônias de Salmonella enterica ser. Typhimurium em cascas de ovos opacos, sanitizados e armazenados sob diferentes temperaturas por 27 dias

\begin{tabular}{lccc}
\hline \multicolumn{1}{c}{ Grupos Experimentais } & \multicolumn{3}{c}{ Dias de armazenamento } \\
& Número de colônias Salmonella enterica ser. Typhimurium \\
\hline Inoculação & $\mathbf{9}$ & $\mathbf{1 8}$ & $\mathbf{2 7}$ \\
\hline Não inoculado & $0 \mathrm{a}$ & $0 \mathrm{a}$ & 0 \\
Inoculado & $25.468,40 \mathrm{~b}$ & $9.900,30 \mathrm{~b}$ & 62,31 \\
\hline Sanitização & & & \\
\hline Não Sanitizado & $13.578,10$ & $7.063,06$ & 17,56 \\
Sanitizado & $11.891,30$ & $2.838,25$ & 45,75 \\
\hline Temperatura & & & \\
\hline $25^{\circ} \mathrm{C}$ & $22.001,90$ & 02,31 \\
$5^{\circ} \mathrm{C}$ & $3.467,50$ & $2.973,19$ & 0 \\
\hline Valores de p & & & $0,0001^{*}$ \\
\hline Inoc. & $0,0004^{*}$ & $0,0001^{*}$ & 0,056 \\
San. & 0,860 & 0,061 & $0,0001^{*}$ \\
Refrig. & 0,837 & 0,473 & 0,056 \\
San. ${ }^{*}$ Refrig. & 0,925 & $0,029^{*}$ & 0,056 \\
Ino. ${ }^{*}$ San. & 0,860 & 0,061 & $0,0001^{*}$ \\
Ino. ${ }^{*}$ Refrig. & 0,837 & 0,473 & 0,056 \\
Ino. ${ }^{*}$ San. ${ }^{*}$ Refrig. & 0,925 & $0,029^{*}$ & 95,23 \\
\hline CV (\%) & 139,09 & 92,37 & \\
\hline
\end{tabular}

Médias seguidas de mesmas letras na coluna não diferem pelo teste $\mathrm{t}(5 \%)$.

* = significância.

Na Tabela 7 estão mostrados o desdobramento da interação entre os três fatores (inoculação, sanitização e refrigeração), no período de 18 dias de armazenamento, para crescimento da Salmonella enterica ser. Typhimurium. Não houve crescimento da Salmonella em ovos não inoculados, mostrando que o procedimento experimental foi adequado. Ovos sanitizados e refrigerados não diferiram $(p<0,05)$ de ovos não inoculados, mostrando que a associação da sanitização após a postura com a refrigeração durante o armazenamento foi eficaz no controle do desenvolvimento dessa bactéria. 
Tabela 7: Desdobramento das interações triplas significativas entre inoculação de ovos com Salmonella enterica ser. Typhimurium e sanitização no período de armazenamento de 18 dias armazenados sob diferentes temperaturas

\begin{tabular}{lc}
\hline \multicolumn{1}{c}{ Tratamentos } & Log UFC/g \\
\hline Inoculação, não sanitização e refrigeração & $3,75 \mathrm{a}$ \\
Inoculação, sanitização e não refrigeração & $2,79 \mathrm{a}$ \\
Inoculação, não sanitização e não refrigeração & $2,52 \mathrm{a}$ \\
Inoculação, sanitização e refrigeração & $0,44 \mathrm{c}$ \\
Não inoculação, não sanitização e não refrigeração & $0 \mathrm{c}$ \\
Não inoculação, não sanitização e refrigeração & $0 \mathrm{c}$ \\
Não inoculação, sanitização e não refrigeração & $0 \mathrm{c}$ \\
Não inoculação, sanitização e refrigeração & $0 \mathrm{c}$ \\
\hline
\end{tabular}

Médias seguidas de letras iguais não diferem pelo teste $\mathrm{t}(5 \%)$.

Na Tabela 8 está apresentado o desdobramento da interação entre inoculação e refrigeração com 27 dias de armazenamento. Esses resultados mostraram que a refrigeração conseguiu diminuir o crescimento bacteriano e, consequentemente, proporcionou ovos de melhor qualidade.

Tabela 8: Desdobramento da interação significativa para número de Salmonella enterica ser. Typhimurium em ovos de casca opaca entre inoculação e refrigeração no período de armazenamento de 27 dias

\begin{tabular}{ccc}
\hline \multicolumn{3}{c}{ Número de colônias de Salmonella enterica ser. Typhimurium (log UFC/g) } \\
\hline \multicolumn{3}{c}{ Inoculação x Refrigeração } \\
\hline \multirow{2}{*}{ Inoculação } & Refrigeração \\
\cline { 2 - 3 } & $\mathrm{SIM}$ & $\mathrm{NÃO}$ \\
\hline $\mathrm{SIM}$ & $0 \mathrm{Ab}$ & $1,68 \mathrm{Aa}$ \\
$\mathrm{NÃO}$ & $0 \mathrm{Ab}$ & $0 \mathrm{Bb}$ \\
\hline
\end{tabular}

Médias seguidas de mesmas letras maiúsculas na coluna e minúscula na linha não diferem pelo teste $t(5 \%)$.

Com relação à frequência de bactérias que penetraram no conteúdo dos ovos submetidos aos diferentes tratamentos em todo o período de armazenamento (Tabela 9), pôde-se observar que, nos tempos zero e 9 dias de armazenamento, não foram encontradas bactérias no conteúdos dos ovos. A presença de bactérias no conteúdo dos ovos pôde ser observada nos tempos de 18 e 27 dias de armazenamento, encontrando-se as bactérias Enterobacteraceae e Salmonella.

Mendes et al. ${ }^{(20)}$ encontraram aos 10 dias de armazenamento a presença de Pseudômonas aeruginosa no conteúdos de ovos de poedeiras. Da mesma forma, De Reu et al. ${ }^{(25)}$ constataram que as bactérias Gram-negativas móveis, como Pseudomonas spp., penetraram facilmente pelos poros das cascas dos ovos e que a contaminação interna ocorreu, frequentemente, após quatro a cinco dias de armazenamento, considerando $\mathrm{pH}$ favorável ao crescimento dessa bactéria entre 7,0 e 9,0. 
Tabela 9: Ocorrência de micro-organismos identificados no conteúdo de ovos opacos (\%) armazenados por 27 dias

\begin{tabular}{|c|c|c|c|c|}
\hline $\begin{array}{c}\text { Armazenamento } \\
\text { (dias) }\end{array}$ & Tratamentos & $\begin{array}{c}\text { Bactéria } \\
\text { (Espécies) }\end{array}$ & $\begin{array}{c}\mathrm{N}^{\circ} \text {. de } \\
\text { Presença }\end{array}$ & $\begin{array}{c}\text { Frequência } \\
(\%)\end{array}$ \\
\hline 0 & nenhum & - & 0 & 0 \\
\hline 9 & nenhum & - & 0 & 0 \\
\hline 18 & $\begin{array}{l}\text { Inoc/ sani/ não refrig. } \\
\text { não inoc/ sani/ refrig }\end{array}$ & $\begin{array}{l}\text { Salmonella } \\
\text { Citrobacter }\end{array}$ & 2 & 50 \\
\hline 27 & $\begin{array}{l}\text { Inoc/ não sani/ não refrig } \\
\text { Não inoc/ não sani/ não refrig }\end{array}$ & Enterobacter & 2 & 50 \\
\hline
\end{tabular}

Cada grupo experimental $\operatorname{com} n=6$.

\section{Conclusões}

Ovos de codornas com casca opaca devem ser refrigerados a $5^{\circ} \mathrm{C}$ durante a estocagem para manter a qualidade física e química, independente do índice de contaminação por bactérias.

A sanitização $\left(5 \mathrm{ppm}\right.$ de cloro) e a refrigeração $\left(5^{\circ} \mathrm{C}\right)$ são eficientes na redução do crescimento da Salmonella enterica ser. Typhimurium em ovos de codornas contaminados experimentalmente.

Ovos com casca opaca quando não refrigerados devem ser consumidos em até 18 dias após a postura.

\section{Referências}

1 Moura AMA, Oliveira NTE, Thiebaut JTL, Melo TV. Efeito da temperatura de estocagem e do tipo de embalagem sobre a qualidade interna de ovos de codornas japonesas (Coturnix japonica). Ciênc. Agrotec. 2008; 32(2): 578-583.

2 Barreto SL de T, Quirino BJ de S., Brito CO, Umigi RT, Araujo MS, Rocha TC, Pereira, CG. Efeitos de níveis nutricionais de energia sobre o desempenho e a qualidade de ovos de codornas européias na fase inicial de postura. R. Bras. de Zootec.2007; 36(1): 86-93.

3 Bordin RA, Pereira CAD, Eboli M, Artilheiro R, Freitas C. Avaliação microbiológica da eficiência do processo de fumigação em ovos incubáveis de codornas japonesas (Coturnix coturnix japonica). Arq. Inst. Biol. 2005;.72 (supl.1):36.

4 Oliveira DD, Silva EN. Salmonella em ovos comerciais: ocorrência, condições de armazenamento e desinfecção da casca. Arq. Bras. Med. Vet. Zootec. 2007; 52(6): 655-661.

5 Andrade MA, Café MB, Jayme SV, Rocha PT, Leandro NSM, Stringhini JH. Avaliação da qualidade bacteriológica de ovos de galinha comercializados em Goiânia, Goiás, Brasil. Ci. Anim. Bras. 2014; 5(4): 221-228.

6 Stringhini MLF, Andrade MA, Mesquita AJ, Rocha TR, Rezende,PM, Leandro NSM. Características bacteriológicas de ovos lavados e não lavados de granjas de produção comercial. Ci. Anim. Bras. 2009; 10(4): 1317-1327.

7 Souza P, Souza HBA, Barbosa JC, Gardini CHC, Neves MD. Effect of laying hens age on the egg quality maintained at room temperature. Ciência e Tecnologia de Alimentos. 1997; 17(1): 49-52.

8 Scott TA, Silversidest B. The effect of storage and strain of hen on egg quality. Poult. Sci. 2000; 79:17251729.

9 Wilks C, Parkinson G, Young P. International review of Salmonella Enteritidis (SE) epidemiology and control polices. Rural Industries Research and Development Corporation. 2000. Disponível em http://rirdc. 
gov.au/reports/eggs. Acesso em: 25 set. 2009.

10 Fernández A, Lara C, Loste A, Calvo S, Marca MC. Control of Salmonella enteritidis phage type 4 experimental infection by fosfomycin in newly hatched chicks. Comparative Immunology, Microbiology and Infectious Disease, Oxfor. 2001; 24: 207-216.

11 BRASIL. Ministério da Agricultura, Pecuária e Abastecimento. Secretaria da Defesa Agropecuária. Instrução Normativa n. 62 de 26/08/2003. Publicada em 18/09/2003. Métodos analíticos oficiais para análises microbiológicas para controle de produtos de origem animal e água. Brasília. DF: MAPA, 2008. 123 p. Disponível em http://www.agricultura.gov.br/. Acesso em: 30 set. 2009.

12 SAS - STATISTICAL ANALYSES SYSTEM. 2002. User's guide: statistics. Version 8. Cary: 2002.

13 Laganá C, Pizzolante CC, Togashi CK, Kakimoto SK, Saldanha ESPB, Alvares V. Influência de métodos da debicagem e do tipo de bebedouro no desempenho e na qualidade dos ovos de codornas japonesas. R. Bras. de Zootec. 2011; 40(6): 1217-1221.

14 Deeming, D C. Factors affecting hatchability during commercial incubation of ostrich (Struthio camelus) eggs. British Poultry Science.1995;36: 51-65.

15 Silversides FG, Budgell K. The relationships among measures of egg albumen height, $\mathrm{pH}$, and whipping volume. Poult. Sci. 2014; 83: 1619-1623.

16 Samli HE, Agma A, Senkoylu N. Effects of storage time and temperature on egg quality in old laying hens. J. Appl. Poult. Res.2005; 14:548-553.

17 Pinto AT, Silva EN. Ensaios de penetração de Salmonella Enteritidis em ovos de galinha com diferentes qualidades de casca, submetidos ou não a lavagem industrial e a duas temperaturas de armazenagem. Arq. Bras. Med. Vet. Zootec. 2009; 61(5):1196-1202.

18 Figueiredo TC, Cançado SV, Viegas RP, Rêgo IOP, Lara LJC, Souza MR, Baião NC. Qualidade de ovos comerciais submetidos a diferentes condições de armazenamento Arq. Bras. Med. Vet. Zootec. 2011; 63(3): 712-720.

19 Araújo IC, Mesquita MA, Andrade MA, Castejon FV, Café MB, Arnhold E, Leandro NSM. Efeito do período e temperatura de armazenamento de ovos férteis sobre o rendimento de incubação e características de qualidade de codornas neonatas. Arq. Bras. Med. Vet. Zootec. 2015; 67(6): 1693-1702.

20 Mendes FR, Leandro NSM, Andrade MA, Café MB, Santana ES, StringhinI JH. Qualidade física, química e microbiológica de ovos lavados, armazenados sob duas temperaturas e contaminados experimentalmente com Pseudomonas aeruginosa. Ci. Anim. Bras. 2014; 15(4): 444-450.

21 Jones DR, Musgrove MT. Effects of extended storage on egg quality factors. Poult. Sci. 2005; 84: 17741777.

22 Sabrani M, Payne CG. Effect of oiling on internal quality of eggs stored at 28 and $12^{\circ} \mathrm{C}$. Poult. Sci .1978; 19: $567-571$.

23 Leandro NSM, Deus HAB, Stringhini JH, Café MB, Andrade MA, Carvalho FB. Aspectos de qualidade interna e externa de ovos comercializados em diferentes estabelecimentos na região de Goiânia. Ci. Anim. Bras. 2005; 6(2): 71-78.

24 Jones DR, Curtis PA, Anderson KE, Jones FT. Microbial contamination in inoculated shell eggs. II Effects of layer strain and egg storage. Poult. Sci. 2004; 83: 95-100.

25 De Reu K, Grijspeerdt K, Heyndrickx M, Uyttendaele M, Debevere J, Herman L. Bacterial shell contamination in the egg collection chains of different housing systems for laying hens. British Poultry Science. 2006; 47(2): 163-172. 